\title{
The socially extended mind
}

\author{
Shaun Gallagher \\ Lillian and Morrie Moss Chair of Excellence \\ Department of Philosophy \\ University of Memphis (USA) \\ School of Humanities \\ University of Hertfordshire (UK) \\ s.gallagher@memphis.edu
}

\begin{abstract}
Thinking, or knowledge getting, is far from being the armchair thing it is often supposed to be. The reason it is not an armchair thing is that it is not an event going on exclusively within the cortex.... Hands and feet, apparatus and appliances of all kinds are as much a part of it as changes within the brain. (John Dewey 1916, 13-14).
\end{abstract}

The concept of the extended mind, as introduced by Clark and Chalmers (1998) was meant in part to move beyond the standard Cartesian idea that cognition is something that happens in a private mental space, "in the head." Elsewhere (Gallagher 2011; Gallagher and Crisafi 2009), I've pursued a liberal interpretation of the extended mind, suggesting that we consider cognitive processes as constituted in various social practices that occur within social and cultural institutions. This idea of the socially extended mind builds on the enactive idea of social affordances. Just as a notebook or a hand-held piece of technology may be viewed as affording a way to enhance or extend our mental possibilities, so the use of various institutional procedures and social practices may offer structures that support and extend our cognitive abilities.

In this paper I review the arguments that underscore this liberal interpretation and some examples that help to make the case. I also explain why an enactive rather than a functionalist approach allows for a better defense against various criticisms of the extended mind hypothesis. Finally, I briefly explore some implications of the concept of the socially extended mind for social and political thought, especially in the context of critical theory.

\section{The parity principle}

The parity principle, as defined by Clark and Chalmers (1998) is central to their concept of extended mind. It states: 
If, as we confront some task, a part of the world functions as a process which, were it to go on in the head, we would have no hesitation in recognizing as part of the cognitive process, then that part of the world is (so we claim) part of the cognitive process. (Clark and Chalmers 1998, p. 8)

Despite their intention of liberating cognitive processes from a strictly headbound, brain-bound set of operations, if the standard, as stated, is whether a process could go on 'in the head', this remains a relatively conservative principle that continues to measure cognition in terms of the traditional conception of the mind. This conservative reading suggests that a process outside of the head counts as cognitive only if in principle it could be accomplished in the head conforming to the Cartesian concept of mental process as something that would normally happen in the head. Thus, we might think of some mental processes as happening "out there" in the world, yet still have a principled reason to limit mental processes to the kinds of things that fit a relatively standard model of the mind.

Clark (2008, p. 114), consistent with his functionalist position, rejects this interpretation, insisting that the parity principle should not be interpreted as requiring any similarity between inner and outer processes (also Wheeler (2006). The worry that comes along with this more liberal interpretation is that the concept of mind gets overextended to include any process in the world (the "cognitive bloat" worry [see Rupert 2004]). Thus, even as he allows for the liberal interpretation of the parity principle, Clark starts to tighten it up again with a set of additional criteria that need to be met by external physical processes if they are to be included as part of an individual's cognitive process. He lists three such criteria.

1. That the external resource be reliably available and typically invoked.

2. That any information thus retrieved be more-or-less automatically endorsed. It should not usually be subject to critical scrutiny (unlike the opinions of other people, for example). It should be deemed about as trustworthy as something retrieved clearly from biological memory.

3. That information contained in the resource should be easily accessible as and when required. (Clark 2008, 79)

The parity principle plus these criteria rule over Clark and Chalmers' primary and much discussed example of Otto and Inga. On the one hand Inga (in remembering the location of a museum) employs her normal biological memory and reflects "... a normal case of belief embedded in memory." Otto, on the other hand, has a poor memory and "... relies on information in the environment to help structure his life. ... For Otto, his notebook plays the role usually played by a 
biological memory" (Clark and Chalmers 1998, 12-13). Accordingly, Otto's belief about the location of the museum supervenes on devices that lie "beyond the skin" when in fact Otto engages with those non-neural devices. There are numerous good examples of how we can enhance our cognitive performance with technology - iPhones, GPS, Google, etc. We seemingly are able to store our memories, and activate beliefs about where things are located, using such instruments. I can't remember where the restaurant is, but I, plus my technology, can.

One problem with this example is that it frames the discussion with a concept of the mind that the extended mind hypothesis is really trying to challenge. It focuses on specific kinds of mental state - belief, or belief embedded in memory, plus the desire to find the museum - explicates the three criteria that seem to apply to such mental states, and then generalizes the criteria to apply to all cognitive processes. The controlling conception of the mind that guides this analysis, then, is that the mind is constituted by beliefs, desires, and other propositional attitudes, and for Clark and other extended mind theorists (e.g., Clark 2008; Rowlands 2009), by representations and informational states as well. But neither the standard belief-desire psychology nor these criteria necessarily apply to all cognition, especially if one thinks of cognition in terms of enactive cognitive processes and activities, e.g., problem solving, interpreting, judging, rather than in terms of mental states or contents.

Accordingly, these criteria seem not just too conservative, but wrongheaded. Each of them, for example, involves matters of degree. It seems possible that some instrument that allows me to think through a problem, and without which I would not be able to think through the problem (see, e.g., the example of the legal system developed below), is neither as reliably available (1), nor as easily accessible (3), as my notebook. Should that automatically exclude it as part of my cognitive process if it subvenes my effective cognitive solution? Moreover, certain institutional or collective practices that subvene my cognitive performance may introduce greater stability than is available in a single biological system.

The second criterion, concerning automatic endorsement and a lack of critical scrutiny, is also suspect. But why should some process that would otherwise count as a cognitive process not count as a cognitive process because it requires critical scrutiny, which is itself a cognitive process? Taking a critical metacognitive perspective on a problem-solving act of cognition, is a frequent (and often a much encouraged) cognitive process. Such critical processes, moreover, may sometimes necessitate a certain institutional or collective arrangement. That is, some critical perspectives clearly involve processes that supervene on a social institution, and may do so in a way that is even more trustworthy or reliable, than biological memory.

The violation of these criteria, and any lack of parity with internal mental states, should not disqualify such processes from being considered cognitive if they are processes to which the human organism is linked in the right way, that is, "in a two-way interaction, creating a coupled system that can be seen as a cognitive system in its own right" (Clark and Chalmers 1998, p. 8). 


\section{Mental institutions}

In contrast to the constrictive effect of these criteria, I argue for a liberal, and specifically social extension of the extended mind hypothesis. I appeal to certain social practices and institutions that are what we might call 'mental institutions' (Gallagher and Crisafi 2009), in the sense that they are not only institutions with which we accomplish certain cognitive processes, but also without which such cognitive processes would no longer exist. They are at least enabling conditions, and on the most liberal reading, constitutive of those processes. ${ }^{1}$ Examples include things like legal systems, research practices, and cultural institutions. In each case a mental institution

1. includes cognitive practices that are produced in specific times and places, and

2. is activated in ways that extend our cognitive processes when we engage with them (that is, when we interact with, or are coupled to them in the right way).

I've suggested that the legal system is a good example (Gallagher 2011; Gallagher and Crisafi 2009). Consider, for example, a contract or legal agreement which is in some real sense an expression of several minds externalized and extended into the world, instantiating in external memory an agreed-upon decision, adding to a system of rights and laws that transcend the particularities of any individual's mind. Contracts are institutions that embody conceptual schemas that, in turn, contribute to and shape our cognitive processes. They are not only the product of certain cognitive exercises, but are also used as tools to accomplish certain aims, to reinforce certain behaviors, and to solve certain problems. Institutions of property, contract, rights, and law not only guide our thinking about social arrangements, for example, or about what we can and cannot do, but allow us to think in ways that were not possible without such institutions. Insofar as we cognitively engage with such tools and institutions we extend and transform our cognitive processes.

The legal system is constructed in part in these cognitive processes. Legal practices, the formation of legal judgments, the administration of justice, the application of law to particular cases, are, among other things (such as exercises of power) cognitive. They do not, however, happen simply in the individual brains of judge, jury, defense attorney, prosecutor, etc. Of course we usually think of judgments as happening in the privacy of one's own head. But some judgments supervene on extra-neural practices and processes that guide them or that allow manipulation of a large amount of empirical information. In a court of law, for example, testimony is produced according to rules of evidence, and judgments are made following a set of rules that are established by the system. The process in which the judgments get made will depend on a number of people remaining cognitively engaged with a body of law, the relevant parts of which

${ }^{1}$ See De Jaegher, Di Paolo, and Gallagher (2010) for the distinction between 'contextual factor', 'enabling condition', and 'constitutive process'. 
come to the fore because of the precise particulars of the case, as the proceedings develop.

Consider an example that involves three different scenarios (see Crisafi and Gallagher 2010). Alexis is given a set of facts and is presented a collection of evidence and is asked to judge the legitimacy of a certain claim that is being made.

(1) In the first scenario she is asked to make her judgment on the basis of her own subjective sense of fairness, weighing the evidence entirely in her own head.

(2) In the second scenario experts specify the kind of questions or considerations she can address.

(3) In the third scenario experts further provide possible answers and a set of rules to follow in making her decision.

In the first scenario Alexis seemingly does all of the work in her own head. In the second, there may be less cognitive effort on her part since she did not have to draw up the questions, and the possible answers were already provided. Yet, it's clear that cognition is socially extended across the legal institutional practices in all the scenarios, since even in (1) Alexis is presented the evidence and given a predetermined task. She doesn't think these up on her own. In none of these cases can Alexis' thinking be reduced to purely 'in the head' processes. The cognition involved is distributed. There is a distribution across a number of participants including the experts, where the distribution is different in each scenario. In (3) we might think that there is not only less cognitive effort going on in Alexis' head -- she not only doesn't have to draw up the questions and possible answers, she doesn't have to produce the principles or rules required to make the judgment. There may be less cognitive effort going on in the heads of the experts too, since what they provide to Alexis (answer types and rules) may be pre-established in the legal system, instituted by previous practice. Indeed, we could say that such questions, possible answers, and rules create the tracks along which the cognitive processes must run to keep it, literally, legitimate. The answer types and rules are part of a system - stored in a system - a system previously established in cognitive processes, and maintained in textual, technological, institutional procedures or cultural practices. The relevant elements of the system were previously established in processes that we would certainly call cognitive, and likely depend on a more wide-ranging set of (cognitive) justifications. When individuals like Alexis and the experts become engaged with the system in the right way, the system does some of the cognitive work.

Judgments, then, are not necessarily confined to individual brains, or even to the many brains that constitute a particular court. They emerge in the workings of a large and complex institution. Yet these judgments and legal proceedings are cognitive processes that then contribute to the continued working of the system in the form of precedents. The practice of law, which is constituted by just such cognitive and communicative processes, is carried out via the cooperation of 
many people relying on external (and conventional) cognitive schemas and rules of evidence provided by the legal institution itself.

Judgments made in such contexts, and the specific kind of judgments that are made, are forms of cognition that supervene on a large and complex system without which they could not happen. Indeed, these cognitive practices are such that in principle they could not happen just in the head. Even in the case of a highly trained attorney who seemingly does what she does in her head, what she does, and what makes it the kind of cognition that it is, depends not only on the fact that she has previously engaged in the workings of the legal system (receiving her training and tuning her cognitive abilities in law school by following specific practices of that educational institution), but on the ongoing workings of the legal system since what she engages in, i.e., the particular cognitive process of forming a legal judgment, is what it is only in that system. It's not difficult to imagine a specific kind of question that would never even come up if there were no legal system. The legal system in effect helps to generate certain cognitive events, sometimes creating perplexities and problems of a purely legal nature, and sometimes helping to resolve them. An individual required to make judgments about the legitimacy of certain arrangements thus interacts with the legal institution and forms a coupled system in a way that allows new cognitive processes to emerge - cognitive processes that would otherwise not be possible. Take away the external part of this cognitive process take away the legal institution - and "the system's behavioural competence will drop, just as it would if we removed part of its brain" (Clark and Chalmers 1998, p. 9).

If we think of the mind not as a repository of propositional attitudes and information, or in terms of internal belief-desire psychology, but as a dynamic process involved in solving problems and controlling behavior and action - in dialectical, transformative relations with the environment - then we extend our cognitive reach by engaging with tools, technologies, but also with institutions. We create these institutions via our own (shared) mental processes, or we inherit them as products constituted in mental processes already accomplished by others. We then engage with these institutions - and in doing so, participate with others to do further cognitive work. These socially established institutions sometimes constitute, sometimes facilitate, and sometimes impede, but in each case enable and shape our cognitive interactions with other people.

Such institutions allow us to engage in cognitive activities that we are unable to do purely in the head, or even in many heads. If we are justified in saying that working with a notebook or a calculator is mind-extending, it seems equally right to say that working with the law, the use of the legal system in the practice of legal argumentation, deliberation and judgment, as well as the cognitive processes involved in the enforcement of law for purposes of controlling behavior are mind-extending too. This view pushes us beyond the strictly defined parity principle and challenges the conservative criteria endorsed by Clark and his colleagues. It also suggests that cognition doesn't simply extend from the brain outward to incorporate tools, technologies, and institutions, but that it sometimes works from the outside in; tools, technologies and institutions often 
shape our cognitive processes, make our brains work in certain ways, and may even elicit plastic changes in neuronal structure.

\section{Following directions}

This way of thinking about mental institutions motivates a significant research agenda, so that from here we could move in a number of directions. One set of questions that needs to be explored is how the idea of the socially extended mind relates to issues of development and social cognition. In this regard one might start with the idea that the family is ontogenetically the first institution, and ask how basic embodied and situated processes of primary and secondary intersubjectivity pull the infant into cognitive habits that shape all further learning, and that become linguistic (and narrative) practices that are further educated in all other social institutions encountered by the child (Gallagher and Hutto 2007).

One could further explore how participatory sense making (De Jaegher and Di Paolo 2007) works within specific institutions. As enactive approaches to cognition have suggested, sense-making processes involve a form of social interaction that has a certain autonomy; that is, such interactive processes are not necessarily under an individual agent's complete control, but often transcend the agent's subjective processes (De Jaegher, Di Paolo, and Gallagher 2010). Social interaction and participatory sense making specifically involve patterns of engagement that can acquire their own form of self-organisation. In the context of extended cognition, where we can speak of interaction with institutions as well as with tools, instruments, technologies, etc., the point is that cognition just is any interaction or engagement that produces meaning for the agent, where the production of meaning is not just an individual enterprise. Participatory sense making is always shaped by super-individual norms and institutional practices.

A third direction is almost too obvious to mention. One could investigate the different ways that particular kinds of institutions extend cognition. I've argued that the use of a legal system to solve a legal problem constitutes a case of complex "epistemic action," and is an instance of extended cognition. The legal system, however, is just one example and we have only scratched the surface in our conceptual analysis of it as a mental institution. Clearly we could expand on this by taking into consideration empirical studies that show precisely how cognition is shaped by various practices found, not only in the legal system, but in various institutions - including educational, cultural, entertainment, military, corporate, religious, scientific, and so forth. Consider, for example, the cognitive work involved in scientific research - would such work be possible - or would it be what it is - without the kinds of things and institutions that make it happen? This may include labs, scientific practices and procedures, journals and publication practices, funding agencies - all of which carry scientific thinking along and make science what it is.

In the remainder of this paper I want to pursue two other directions. First, I want to take the discussion of the socially extended mind back to the ongoing extended mind debates between Clark, Wheeler, Rowlands, et al. on one side, and 
Adams, Aizawa, Rupert, et al. on the other side. In this regard I want to suggest that an enactive approach to the various facets of this debate can offer a better defense of the extended mind hypothesis from objections that involve cognitive bloat, the so called causal coupling-constitution fallacy, and the mark of the mental. Second, I want to take the concept of the socially extended mind forward into contexts that involve questions about social critique and institutional change. In this regard I will suggest that the idea of the socially extended mind can provide a useful tool for critical theory.

\section{Some ongoing debates about the extended mind}

It certainly seems that if critics are worried about the relatively conservative conception of the extended mind defended by Clark and Chalmers (1998), they may be even more worried about what is seemingly a "larger" and more liberal socially extended concept of the mind. I want to consider what seem to me to be the three main objections to the extended mind raised by its critics.

\section{The causal coupling-constitution fallacy}

Even if externalities play a role in cognition, according to Adams and Aizawa (2009), they play only a contextual, enabling or causal role rather than a constitutive role. On their internalist concept of the mind, all of the real constituting action of cognition happens in the brain, even if it is in some way supported or facilitated by external elements. Some factors are clearly causal; the air we breath, for example, is necessary for cognition to take place, but neither the air nor our respiration is a constitutive part of cognition. More generally the fact that something is causally coupled to our cognitive system does not make it part of the cognitive system (Adams and Aizawa 2010).

Clearly Adams and Aizawa are correct to suggest that some factors are causal and not constitutive. For example, in a recent study of judicial decisions Dansiger et al. (2011) have shown that the rational application of legal reasons does not sufficiently explain the decisions of judges. Whether the judge is hungry or satiated may play an important role. Their study showed that the "percentage of favorable rulings drops gradually from $\approx 65 \%$ to nearly zero within each decision session [e.g., between breakfast and lunch] and returns abruptly to $\approx 65 \%$ after a [food] break." This suggests that "judicial rulings can be swayed by extraneous variables that should have no bearing on legal decisions." (Dansiger et al. 2011, 1). Some embodied theorists might object to such factors being called 'extraneous' to the cognitive process, but they are surely extraneous to the extent that they are not included in the normative factors and arrangements that constitute the legal judgment. The state of the judge's stomach may be a causal factor in her judgment, but the rules of evidence and the specific legal practices that have been followed in the hearing - the mental institutions - are in fact constitutive: they make the judgment the legal judgment that it is. The idea that $\mathrm{x}$ is a causal factor assumes we are capable of thinking in a certain way independently of $\mathrm{x}$, and given some alternative set of causal factors. Starving the judge or bringing him a sandwich (highly recommended if you are being 
sentenced) will not guarantee that the judgment will go one way or another. The idea that $\mathrm{x}$ is a constitutive factor, however, suggests that it may not be possible to think that way without $\mathrm{x}$. Take away rules of evidence or some set of legal practices and the judgment ceases to be the judicial thing that it needs to be.

Another example may help to clarify this. Consider what we might call a case of manipulated thinking, i.e., our decision making process is manipulated by certain corporate or institutional practices. Paul Slovic's research on altruism provides a benign example. Slovic's group has studied empathy and altruistic behavior and has shown that the kind of information provided to potential charitable donors will affect not only their decision to act altruistically by making a donation, but will determine the amount that they donate. It's known, for example, that a higher number of victims involved in a major disaster or in genocide will not necessarily generate more altruistic behavior than a smaller number (Figure 1).

A

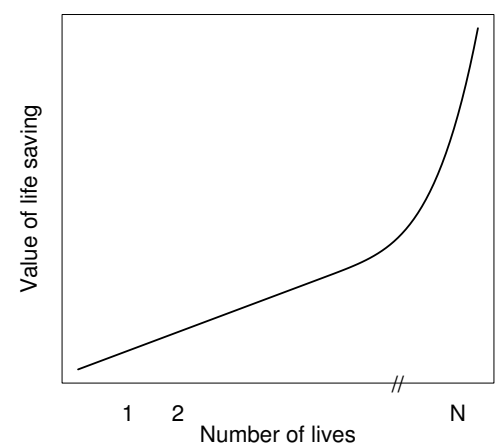

B

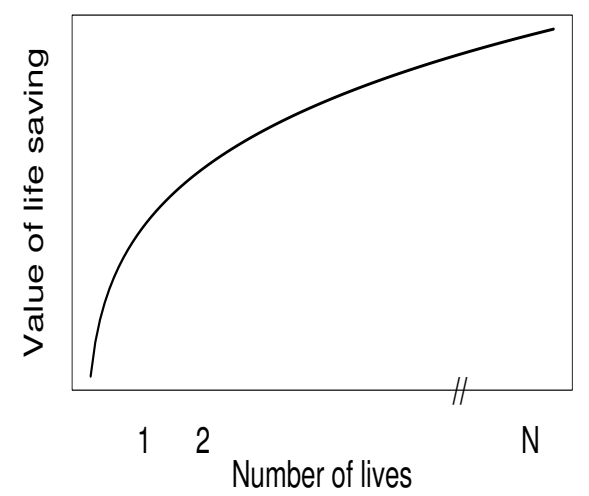

Figure 1: Graph A represents a normative utilitarian model that suggests that the larger loss of life will motivate a greater degree of altruism. Graph B represents something closer to actual behavior. The greater the loss of life the more abstract and emotion-less it becomes with only slight increases in altruistic behavior after the first few cases. (Figures from Slovic 2007).

When someone is presented with a set of statistics, the cold although convincing facts about the enormity of the problem to be addressed, they show less altruistic behavior (make less donations) than when they are presented with the image and or personal story of one individual. Alternatively, when presented with the personal details concerning the suffering of another individual person, people experience a variety of emotional reactions and show a higher degree of altruistic behavior (Figure 2). Thus, when information about others is presented in a way that elicits empathic responses, donations are greater in comparison to when this information is processed in a detached, abstract, or intangible way (Dickert \& Slovic 2009). Charitable organizations capitalize on this fact to secure donations for humanitarian aid purposes (Small, Loewenstein \& Slovic 2007). 


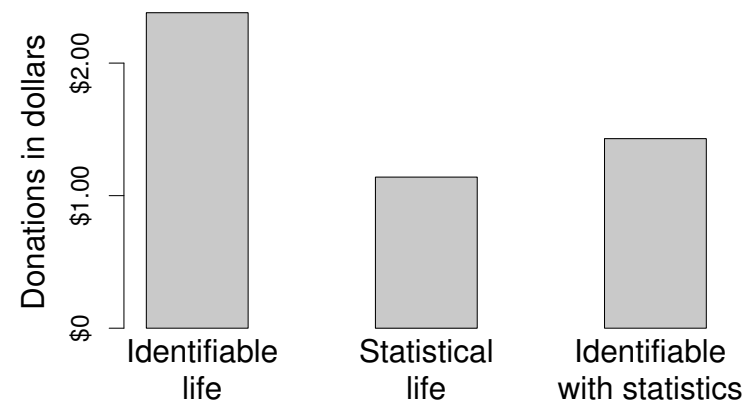

Figure 2: Mean donation in cases when subjects were told that donations would help support a particular individual vs. when subjects were told that donations would support relief efforts addressing problems summarized by a set of statistics, vs. when they were presented with both the statistics and the individual case. (From Slovic 2007).

This kind of presentational practice (sometimes benign, sometimes not) may play a causal role shaping the way people decide to donate (in the same way a priming effect may cause a certain behavior or way of thinking). But if a charity organization adopts this practice in presenting its solicitations, then this instituted practice may help to constitute the way its members or management staff think or decide to do things, may constitute the very way that they think about solving problems - or in Clark's preferred phrase, this practice enters into the agent's cognitive system. Clearly, then, some externalities - institutional practices and policies - may play a constitutional role in making cognition what it is.

\section{Cognitive bloat}

The inclusion of mental institutions in the notion of extended mind seems to be a good example of the cognitive bloat that Rupert (2004) worries about, where cognition extends to all kinds of processes that seem at odds with the very notion (or the very traditional notion) of cognition. If my mind is extended by my use of Google to solve a problem, does that mean that cognitive processing is ongoing everywhere in cyberspace? Rowlands (2009), in response to the cognitive bloat argument, has suggested that part of what qualifies a process as cognitive is that it is owned by the agent. This notion of ownership, however, doesn't seem to apply to mental institutions - no one owns the legal system, for example. Here, however, we might appeal to a Lockean notion of ownership: ownership is constituted by the work invested. More precisely, it is the fact that I am working and engaged in the right way with mental institutions that makes them a constituent part of my cognitive processes. Only so far as I am properly engaged with these institutions (or with notebooks or pieces of technology), do they contribute to the constitution of my cognitive processes. If I am not engaged with them (just as some neuronal processes in my brain may remain unactivated in specific circumstances) then they are not cognitively activated. Rupert's (2009, 131) notion of "densely interactive processes" - "those in which the organism and 
environment affect each other in an ongoing way," which we might call enactive couplings involving both neural and non-neural factors -- expand the defining limit for the concept of cognition. What constitutes the cognitive is tied to the specific kind of engagement that's involved.

The "specific kind" of enactive couplings includes my engagement with social customs and practices. In solving a problem like keeping my cattle in my pasture, my bodily manipulations of a set of wooden poles and wire are not part of the cognitive process; but my engagement with the particular local custom/practice of solving this problem with a fence (and even a specific kind of fence) is a cognitive part of the problem solving. If there were no local custom in this regard, the cognitive processes required to solve the problem would be more narrowly "in the head." In each case, cultural practices, local know-how in the form of established practices, etc., in either formal or informal ways, enter into and shape the thinking process. Without such cultural practices, rules, norms, etc. the thinking - our cognitive processes - would be different.

It's important to be clear about what is claimed in the extended mind hypothesis. It's easy to confuse the issue. Larry Shapiro (2009), for example, in his review of Adams and Aizawa (2008), offers the following example.

When I dig a hole, the shovel aids me in this task, and it may even be true that I could not dig the hole without the shovel. But this does not extend my musculature into [things that are] independent of my musculature. According to Adams and Aizawa the same story holds true, mutatis mutandis, for cognition and its external accessories.

Clearly the claim should not be that I extend my musculature - the point would rather be that the digging is something extended from my bodily musculature across the shovel and into the ground. Take away the musculature, or the shovel, or the ground, and nothing like digging would be going on. Likewise, no one claims that I extend my brain by using a notepad, or by engaging with an institutional practice, but rather that I extend the cognitive process. Yet, as we know from neuroscience, such extensions may transform our brain; there are, for example, plastic remappings of somatosensory cortex for ego-centric coding of arm position when we use tools (Bassolino et al. 2009); and there are the famous studies of the enlarged hippocampi of London taxi drivers (Mcguire et al. 2000). Such changes are relevant if, as one may presume, taxi drivers enactively use streets and landmarks in the surrounding city to orient and find their way, and not simply some internalized map. It seems likely that in the future hippocampi of taxi drivers may shrink as they transition to full use of GPS technology, and likely other parts of the brain may change to support this use. If prolonged cognitive practices in an urban transportation system can change one's brain, then it is not unlikely that prolonged cognitive practices in a legal system could do the same for attorneys, judges, etc. Such plastic changes in the neural elements of cognition may be evidence that the right kind of coupling has been established. Unlike the parity principle, however, it's not a matter of functional equivalence: e.g., one can 
have either a large hippocampus or a GPS doing the same work. Rather, cognition is in the dynamic coupling of neural and non-neural processes that make cognition what it is. The point here is that as we engage with externalities in specific ways our cognitive processes - including our neural processes, but not just our neural processes - are transformed.

\section{The mark of the mental}

Adams and Aizawa (2008) develop a further objection to the extended mind hypothesis, contending that where cognition stops and something non-cognitive begins can be determined by "the mark of the mental," and that external processes do not have this mark. The more positive outcome of their first causal couplingconstitution objection is their proposal for a specific mark of the mental.

If the fact that an object or process $\mathrm{X}$ is coupled to a cognitive agent does not entail that $\mathrm{X}$ is part of the cognitive agent's cognitive apparatus, what does? The nature of $X$, of course. One needs a theory of what makes a process a cognitive process..... One needs a theory of the "mark of the cognitive" (Adams and Aizawa 2010, p. $68)$.

Their preferred internalist theory is that the mark of the cognitive is "non-derived content" - the kind of representations generated in neural processing. Intrinsic 'cognitive states in normal cognitive agents do not derive their meanings from conventions or social practices ... Whatever is responsible for non-derived representations seems to find a place only in brains' $(2001,48,63)$. But the concept of non-derived content is not on settled ground. As Shapiro (2009) notes, "there is today no received theory of how original content comes to be in the first place." Accordingly, it might be possible to find a theory of non-derived content that is consistent with extended cognition - and one would need to leave that option open, or start begging the question. The latter happens quite easily when one defines the nature of content in terms of the kind of vehicles that can carry it. Others have appealed to intentionality (following Brentano's idea) as the correct mark (e.g., Menary 2009). Again, however, there is a good deal of disagreement about intentionality. Surely, for example, the experience of pain is a mental experience, but is it intentional? (see, e.g., Crane 1998 for discussion). Some, including Husserl and Searle, have argued that not all mental experience is intentional. Furthermore, the problem this solution is meant to solve is simply repeated again if, as some claim, intentionality is purely internalistic (see, e.g., Horgan and Tienson 2002), while others claim, alternatively, that non-derived intentionality is actually the kind of embodied, enactive, and socially constituted phenomenon found in the phenomenological or neo-pragmatic concept of motor or operative intentionality (Gallagher and Miyahara, in press).

Such considerations should be set aside because the question about the mark of the mental is just not the right question, whatever the right answer might be to it. Within the terms of this particular debate, the concept is too closely tied to the traditional conception of the mind that is being challenged by the extended 
mind hypothesis. To accept the terms of the debate is to already concede too much. One can see this in the fact that the debate about the mark of the mental is often framed in terms of the content-vehicle distinction, a distinction that has an important clarifying function when we think of the mind on an orthodox representational or functionalist model, but one that should be abandoned on an enactive conception of the extended mind. On the more enactive view, we need to conceive of the mind/brain, not as the place where all the mental processing and representing happens, but as part of a larger, embodied and enactive system. Cognition is not about content (whether non-derived or derived) being carried by vehicles (whether neural or extra-neural), but is an enactive and emotionally embedded engagement with the world through which we solve problems, control behavior, understand, judge, explain, and generally do certain kinds of things much of that constitutionally shaped by tools, environmental factors, social practices, etc. On this conception, the mind is constituted primarily by just such activities, whereas propositional attitudes, mental states, representations, and any talk of vehicles or contents (whether derived or non-derived) are derivative and are inexplicable except in reference to such activities.

\section{Socially extended mind and critical theory}

The idea of the socially extended mind motivates a critical normative perspective not usually taken up in the cognitive science literature on the extended mind. Cognitive processes, as they are shaped in both institutional and technological structures and practices, can allow us to see certain possibilities even as they blind us to others. We should take a closer and critical look at how social and cultural practices either productively extend or, in some cases, curtail mental processes. We know that certain technologies and media, as they are strategically used for consciously determined objectives by various institutions for various reasons, offer possibilities, which at the same time carry our cognitive processes in specific directions. Such processes can have profound effects on us, and on our thinking. It is therefore important to ask what such mechanisms or practices or institutions do to us as agents and as subjects of cognition. I think that these kinds of questions fall squarely into the concerns of critical social theory.

At least on one critical theory approach, inspired by Habermas, the main task would be to expose the various epistemic actions and operations carried out by cognitive agents operating in frameworks established by institutional practices that distort (or at least shape) our cognitive processes, in order to promote ethical or political reflection on such practices. Of course any critical theory worth its salt would then turn its critical reflective eye on the way we carry out such ethical and political (and perhaps inevitably ideologically informed) reflections to further inquire about the instituted practices of such reflections. If this task is to be met by critical theory, then it needs to enlist the help of, or perhaps itself to become a kind of critical cognitive science (Chodery and Slaby 2011).

Consider, for example, that cognitive studies of decision making show that even if one seems to be engaged in a solitary set of mental reflections in one's head, decision making is really a matter of embodied, emotion-rich, 
environmentally modulated processes. Even if we are trained as hard-nosed rationalist philosophers, or no-nonsense business executives, or data-driven scientists, research has shown that our decisions are influenced by various institutional practices. The examples are too numerous to mention, but they include the spatial arrangement of supermarkets, the architectural design of churches, the rules of evidence and the structure of allowable questions in a courtroom trial, and a variety of rituals and practices designed to manipulate our emotions (see, e.g., Slavic's experiments, discussed above). Sometimes the effects are unintentional and are accidental features of the institutional environment; sometimes they are the result of strategic planning.

The institutional practice of charities that specifies use of a successful presentation style may be an obvious and relatively innocuous example of how different media enter into the cognitive process, and how institutions may use media to elicit certain behavior. I take this to be a case of socially extended cognition because the process of decision making changes, indeed is manipulated, when one set of external factors is introduced rather than another - that is, when images plus narrative are part of the process rather than statistical data - and the whole process is mediated by a certain institutional practice. From the perspective of critical theory, whether such processes have merely a causal effect on the decisions and behaviors of an audience, or are constitutive of cognition for the strategists, is less important than the outcome - which in either case is to lead our cognitive processes in a certain direction.

The objective of the charitable organization that exploits these means for raising money may be noble, and the outcome, a certain amount of altruistic behavior, may be good for everyone, but one can easily think of other organizations, objectives, and outcomes that may not be so innocuous. The point is, however, faced with such institutional practices, we not only ought to understand, from an efficiency perspective, how precisely they improve (or impede, or distort) cognitive processes of decision making or problem solving, or how we can improve their efficiency - these seem to be questions already addressed by various studies in cognitive science - but also, from a critical perspective, whether these processes improve (or impede, or distort) our communicative practices, our possibilities for action, our recognition of others, our shared and circumscribed freedoms, and so forth.

One might think, however, that critical theory already does this sort of thing in its projects of cultural critique. I don't dispute this. What I suggest is twofold. First, that the concept of the extended mind, if we can get it right, offers a new understanding of what cognition (the mind) actually is and how it works. As such it offers a new perspective for understanding decision making, judging, problem solving, communicative practices, and so forth, which importantly includes reference to the kind of externalities that critical theory ought to be concerned about - institutional practices and procedures, norms, rules, technologies, and so forth. Such externalities not only shape our cognitive processes and thinking, but also play a dominating role in bureaucratic systems, democratic processes, and an extensive range of social, legal, and political phenomena. Accordingly the idea of the socially extended mind at the very least 
offers a new tool for the practice of critical theory. Second, although cognitive science is already studying the kind of cognition that some theorists take to be socially extended cognition, the proposal here is that we give this kind of cognitive science a critical twist.

\section{References}

Adams, F. and Aizawa, K. 2010. Defending the bounds of cognition. In R. Menary (ed.), The Extended Mind (67-80). Cambridge, MA: MIT Press.

Adams, F. and Aizawa, K. 2008. The Bounds of Cognition. Malden, MA: Blackwell.

Bassolino, M., Serino, A. Ubaldi, S. and Ladavas, E. 2009. Everyday use of the computer mouse extends peripersonal space representation. Neuropsychologia, Nov. 18. E-publication prior to print.

Chowdery, S. and Slaby, J. (eds.). 2011. Critical Neuroscience. A Handbook of the Social and Cultural Contexts of Neuroscience. Oxford: Blackwell.

Clark, A. 2008. Supersizing the Mind: Reflections on Embodiment, Action, and Cognitive Extension. Oxford: Oxford University Press.

Clark, A. and Chalmers, D. 1998. The extended mind. Analysis 58.1: 7-19

Crane, T. 1998. Intentionality as the mark of the mental. In A. O'Hear (ed.), Contemporary Issues in the Philosophy of Mind. Royal Institute of Philosophy Supplement (No. 43). Cambridge: Cambridge University Press.

Crisafi, A. and Gallagher, S. 2009. Hegel and the extended mind. Artificial Intelligence \& Society. E-publication ahead of print., November 2009. DOI 10.1007/s00146-009-0239-9

Dansiger, S., Levavb, J. and Avnaim-Pessoa, L. 2011. Extraneous factors in judicial decisions. PNAS. www.pnas.org/cgi/doi/10.1073/pnas.1018033108

De Jaegher, H. and Di Paolo, E. 2007. Participatory sense-making: An enactive approach to social cognition. Phenomenology and the Cognitive Sciences 6 (4): 485-507.

De Jaegher, H., Di Paolo, E. and Gallagher, S. 2010. Does social interaction constitute social cognition? Trends in Cognitive Sciences 14 (10): 441-447.

Dewey, J. 1916. Essays in Experimental Logic. Chicago: University of Chicago Press.

Dickert, S. and Slovic, P. 2009. Attentional mechanisms in the generation of sympathy. Judgment and Decision Making 4: 297 -306.

Gallagher, S. 2011. The overextended mind. Versus: Quaderni di studi semiotici 113-115: 55-66.

Gallagher, S. and Crisafi, A. 2009. Mental institutions. Topoi 28 (1): 45-51.

Gallagher, S. and Hutto, D. 2008. Understanding others through primary interaction and narrative practice. In: J. Zlatev, T. Racine, C. Sinha and E. Itkonen (eds). The Shared Mind: Perspectives on Intersubjectivity (17-38). Amsterdam: John Benjamins.

Gallagher, S. and Miyahara, K. (in press). Neo-pragmatism and enactive 
intentionality. In J. Schulkin (ed.), Action, Perception and the Brain. Basingstoke, UK: Palgrave-Macmillan.

Horgan, T. E. and Tienson, J. L. (2002). The intentionality of phenomenology and the phenomenology of intentionality. In D. J. Chalmers (ed.), Philosophy of Mind: Classical and Contemporary Readings. Oxford: Oxford University Press.

Maguire, E. A., Gadian, D. G., Johnsrude, I. S., Good, C. D., Ashburner, J. Frackowiak, R. S. and Frith, C. D. 2000. Navigation-related structural change in the hippocampi of taxi drivers. PNAS 97 (8): 4398-4403.

Menary, R. 2009. Intentionality, cognitive integration, and the continuity thesis. Topoi 28: 31-43.

Rowlands, M. 2009. The extended mind. Zygon 44 (3): 628-41

Rupert, R. 2004. Challenges to the hypothesis of extended cognition. Journal of Philosophy 101: 389-428

Rupert, R. 2009. Cognitive Systems and the Extended Mind. New York: Oxford University Press.

Shapiro, L. 2009. Review of Fred Adams and Ken Aizawa, The Bounds of Cognition (Malden, MA: Blackwell, 2008). Phenomenology and the Cognitive Sciences.

Slovic, P. 2007. If I look at the mass I will never act: Psychic numbing and genocide. Judgment and Decision Making 2: 79-95.

Small, D. A., \& Loewenstein, G. 2003. Helping a victim or helping the victim: Altruism and identifiability. Journal of Risk and Uncertainty 26: 5-16.

Small, D. A., Loewenstein, G., \& Slovic, P. 2007. Sympathy and callousness: Affect and deliberations in donation decisions. Organizational Behavior and Human Decision Processes 102: 143-153.

Wheeler, M. 2006. Minds, things and materiality. Conference presentation: The Cognitive Life of Things: Recasting the boundaries of the mind (Cambridge University). Forthcoming in C Renfrew and L Malafouris (eds.) The Cognitive Life of Things. McDonald Institute Publications, McDonald Institute for Archaelogical Research, Cambridge. 